\title{
ENSINO DE FILOSOFIA: DESAFIOS E POSSIBILIDADES DA DOCÊNCIA NO ENSINO MÉDIO NA CONTEMPORANEIDADE
}

\author{
TEACHING OF PHILOSOPHY: CHALLENGES AND POSSIBILITIES OF TEACHING IN \\ MIDDLE SCHOOL IN CONTEMPORANEITY
}

Fabio Ronaldo Meneghini dos Santos'

\begin{abstract}
Resumo: Desde o retorno da obrigatoriedade da disciplina de Filosofia ao Ensino Médio, a partir da homologação, Lei № 11.684, 2 de Junho de 2008, desafios são enfrentados na docência da disciplina, dentre estes estão a desvalorização da Filosofia, preconceito e a discriminação da mesma enquanto disciplina do currículo. Um dado importante é que ao ingressar em um curso de licenciatura em Filosofia o estudante não tem presente a realidade escolar e curricular que muitas vezes desafia o docente quanto ao sentido do ensino de filosofia. $O$ que regularmente acontece é que somente após o início do período de estágio obrigatório que há a possibilidade de experimentações práticas de organizar o planejamento para a atividade de ensino, também é nesse momento que nos deparamos com situações nada fáceis tanto para o docente quanto para o estagiário. Tais situações referem-se principalmente a recorrente necessidade de justificar a importância da filosofia perante as outras áreas do conhecimento. Pensamos que a partir desse contexto no qual a docência em filosofia está inserida é preciso problematizar e apontar de que modo é possível a filosofia na escola, considerando de que modo a multiplicidade existencial do jovem estudante do ensino médio interfere na docência da filosofia.
\end{abstract}

Palavras-chave: Didática; Docência Filosofia; Ensino Médio;

\begin{abstract}
From the return of the compulsory discipline of Philosophy to High School, from the homologation of Law No. 11,684, of June 2, 2008 challenges are faced in teaching the discipline, among these are the devaluation of Philosophy, prejudice and discrimination of curriculum discipline. An important fact is that when entering a degree course in Philosophy, the student does not take into account the school and curricular reality that often challenges the teacher as to the meaning of teaching philosophy. What regularly happens is that only after the beginning of the compulsory internship period that there is the possibility of practical experimentation to organize the planning for the teaching activity, it is also at that moment that we come across situations not easy
\end{abstract}


for both the teacher and the teacher. intern. Such situations refer mainly to the recurring need to justify the importance of philosophy to other areas of knowledge. We think that from this context in which teaching in philosophy is inserted it is necessary to problematize and point out how philosophy is possible in the school, considering how the existential multiplicity of the young high school student interferes in the teaching of philosophy.

Keywords: Didactics; High school; Philosophy; Teaching.

\section{INTRODUÇÃO}

Desde que a disciplina de Filosofia retornou ao currículo do Ensino Médio, a partir da homologação da Lei № 11.684, de 2 de Junho de 2008 desafios são enfrentados na docência da disciplina, dentre estes estão a desvalorização da Filosofia, o preconceito e a discriminação da mesma enquanto disciplina do currículo $O$ propósito principal deste artigo que segue é tentar identificar quais são os desafios enfrentados na docência do ensino de Filosofia no Ensino Médio e de que modo é possível o ensino de Filosofia na escola como um dos objetivos específicos.

O restante desse artigo está organizado da seguinte maneira: na seção 2 é apresentado um pouco sobre a questão do Ensino de Filosofia no Ensino Médio; a seção 3 apresenta o histórico do Ensino de Filosofia no Brasil; na seção 4 é apresentado os desafios enfrentados na docência da disciplina de Filosofia; a seção 5 apresento um pouco da minha experiência na docência; e por fim, as conclusões são apresentadas nas seções 6 e 7 respectivamente.

\section{RETORNO DA FILOSOFIA}

A Filosofia retorna ao currículo do Ensino Médio e seu ensino tem sido tema de palestras, seminários, debates entre profissionais da área na intenção de buscar respostas para o mesmo diante da situação que se encontra. Entretanto, questionamentos se fazem presentes na prática diária de estagiários e docentes tais como: de que modo é possivel o Ensino de Filosofia na escola? Como despertar no estudante do Ensino Médio o interesse para a reflexão, o pensamento? A organização curricular do Ensino de Filosofia interfere na prática docente? Como repensar o Ensino de educação básica? Por que ensinar Filosofia? Segundo Cerletti (2015), em seu artigo Didáctica filosófica, didáctica aleatoria de la filosofía:

\footnotetext{
"Encarar filosóficamente la cuestión 'enseñar filosofía' significa entonces tener que identificar o caracterizar la filosofía que se asume para abordar la pregunta y además intentar responder, de manera consecuente, el interrogante '¿qué es aprender filosofía?'. Es decir, habrá que construir un sentido del aprendizaje filosófico y qué vínculo se puede establecer - si es posible hacerlo - entre enseñar y aprender filosofia." (CERLETTI, 2015, p.29)
}

O fato de que, ao ensinarmos filosofia, somos remetidos a responder a essas perguntas, claramente revela que a sustentação do ensino de filosofia é mais do que pedagógica, é propriamente filosófica. O que se considera ser filosofia deveria ter algum tipo de vínculo com a 
forma de ensiná-la, já, pois o que se considera ser filosofia se expressa na maneira de seu ensino. A tarefa de ensinar filosofia não pode estar desligada do fazer filosofia, de forma que filosofia e filosofar se encontram unidos, de igual modo, ocorre com a prática filosófica e o ensino de filosofia. Portanto, o ensino de filosofia tem que ser filosófico.

O mundo atual busca respostas práticas, rápidas e úteis. É difícil encontrar uma utilidade para a filosofia que seja adequada a este contexto atual. Este é um grande desafio para a docência de filosofia, pois o professor precisa conseguir mostrar que a filosofia tem sua utilidade, o que não poderá ser mostrado se o modelo de mera transmissão de conhecimentos continuar se perpetuando. A filosofia não mais encontra sua finalidade sendo vista apenas como mãe das outras disciplinas, agora ela precisa desdobrar seu potencial crítico, se tornando útil ao analisar as potencialidades de sua época. O problema abordado neste trabalho será o ensino de filosofia vazio de sentido e significado. As aulas de filosofia precisam ser um lugar onde possa haver reflexão, dando lugar à atitude filosófica.

O objetivo central do ensino da filosofia é introduzir o estudante à filosofia, ou seja, levá-lo para dentro e inseri-lo numa forma específica de saber, então, a didática do ensino da filosofia deve perseguir em termos gerais, uma dupla finalidade: a) criar mediações pedagógicas que facilitam o processo de aprendizagem; b) promover a transição para a construção da capacidade de pensar por conta própria, de modo que o estudante consiga gradativamente dispensar mediações com a filosofia.

As questões indagadas acima e outras serão tratadas no artigo que segue buscando apontar e problematizar a importância do ensino de Filosofia na escola, bem como contribuir para a reflexão sobre o ensino de filosofia especialmente no que diz respeito à sua contribuição no processo de formação dos jovens que demandam do Ensino Médio.

\section{HISTÓRICO DO ENSINO DE FILOSOFIA NO BRASIL}

A história do Ensino de Filosofia no Ensino Médio no Brasil foi caracterizada por avanços e retrocessos; ou era inserido ou anexado como disciplina, ou então retirado de sua grade curricular. Pensando sobre a questão da presença e ausência da filosofia no currículo da educação básica, o professor Celso Favaretto (2013) destaca que, somente por volta das décadas de 1920 e 30, a filosofia passa a integrar os currículos escolares, de maneira bastante acanhada, sem constituir de fato uma disciplina, concebendo apenas como conhecimento complementar, ora como lógica, história da filosofia, ou moral.

Nos anos 60, a LDBEN equaciona uma Base Curricular para todos os cursos dos até então conhecidos como cursos científicos e/ou clássicos (colegiais), mas como afirma o professor Celso Favaretto: "A filosofia, curiosamente, não obrigatória: ela está no currículo, mas como disciplina optativa e continua a existir nas escolas que já a ministravam" (FAVARETTO, 2013, p.27).

No começo dos anos 70, com a Lei 5.692/71, a filosofia é retirada do currículo escolar. Ocasião em que, segundo Soares (2012, p.23) "dirigentes políticos impuseram um programa de modernização da economia alicerçado na repressão severa contra qualquer mobilização das oposições". As práticas educativas apresentadas como formadoras de opinião pública foram condenadas e eliminadas do currículo escolar da educação formal.

Nos anos 90 ainda que a LDB (2008) recomendasse que o estudante ao concluir o Ensino Médio deveria confirmar domínio das temáticas das disciplinas de Filosofia e Sociologia indispensáveis para o exercício de sua cidadania, observa-se que a disciplina de Filosofia ainda permanecia ocupando um espaço secundário, mantendo-se no grupo dos chamados temas transversais.

Após a homologação da Lei 11.684, de 2 de junho de 2008, a Filosofia volta a ser uma disci- 
plina obrigatória no Ensino Médio, função esta não exercida desde 1961 (Lei n 4.020/61). Diante desse cenário, profissionais envolvidos com o ensino, sobretudo com o Ensino de Filosofia, são novamente convocados a pensar questões fundamentais sobre a disciplina. Porém, oito anos depois, com a reforma do Ensino Médio, em 30 de novembro de 2016, a comissão mista do Congresso Nacional aprova o parecer do relator da matéria e encaminha o Projeto de Lei de Conversão $n^{\circ} 34 / 2016$. Neste documento, foi confirmada a perda do caráter obrigatório das disciplinas de Filosofia e Sociologia do currículo, desconsiderando diversas manifestações contrárias de entidades científicas e de especialistas da área da educação.

\section{DESAFIOS DO ENSINO DE FILOSOFIA}

O cenário presente nas escolas evidencia no atual momento sociocultural o desinteresse verificado e sentido pelos jovens, especificamente no tocante ao produzir seu pensamento reflexivo e crítico. Tal preocupação observada nos coloca diante da difícil tarefa de formarmos pessoas que sejam capazes de refletir, analisar, avaliar e escolher. Sujeitos autônomos, capazes de elaborar argumentos mais críticos acerca dos acontecimentos naturais, das ações e das práticas humanas.

Hoje o que se vê na escola é o desinteresse pela filosofia, pela reflexão e pelo pensamento. Os estudantes sentem dificuldades na escrita e na exposição de seus pensamentos por não desenvolverem a argumentação. Essas são algumas dificuldades que o professor de filosofia vivencia em sua prática. Estudantes desinteressados pelo saber filosófico. A preocupação dos estudantes consiste exclusivamente em respostas rápidas que na maioria das vezes são apresentadas como questões objetivas, de escolha entre certo número de respostas, quando estas na verdade deveriam ser questões descritivas e de desenvolvimento argumentativo. Os estudantes do Ensino Médio querem aprovação, se preparar para o vestibular, fazer um curso técnico profissionalizante, prestar concursos públicos, prepararem-se para o mercado de trabalho.

Enquanto disciplina obrigatória, a filosofia enfrenta consideráveis desafios no seu fazer educacional. Todavia, o primeiro desses enfrentamentos seria responder à comunidade educacional o que seria filosofia. E qual a sua utilidade na contemporaneidade? Assim, "a primeira resposta seria a decisão de não aceitar como naturais, óbvias e evidentes as coisas, as ideias, os fatos, as situações, os valores, os comportamentos de nossa existência cotidiana". (CHAUl, 2008, p.17)

Desta forma, a filosofia não só na contemporaneidade, mais em toda a História da humanidade afirma-se como saber útil e necessário para estabelecer reflexões sérias e sistemáticas sobre toda e qualquer área do conhecimento nos seus mais diversos graus de complexidade. Assim, a filosofia surge como perspectiva de contribuição acadêmica nas mais diversas instituições de Ensino Médio para a formação crítica dos educandos, preenchendo um hiato educacional, ético, estético, crítico, assim como, para a compreensão da inter-relação das áreas do saber enquanto instrumento pedagógico de interação. Essa concepção se fortalece quando se observa que "tanto a epistemologia genética de Piaget quanto o socioconstrutivismo de Vygotsky, apesar de suas diferenças são considerados teorias interacionistas. É por meio de interações que os seres humanos se desenvolvem e aprendem." (MATTAR, 2009, p.113) De forma que atraia os discentes para a construção de um saber mais consolidado na sua prática filosófica, social, educacional e profissional. Todavia, como incentivar a continuidade de um ensino prazeroso nas escolas ou propor ações que possam beneficiar e ampliar esse processo não percebido pelos educandos? "A inserção de novas possibilidades comunicativas, a conectividade, a troca de informações em rede, características do nosso tempo, demonstram que o sujeito já não se encontra ali localizado num espaço-tempo" (COUTO, 2010, p.28). 
Pensar em um ensino de filosofia para adolescentes que faça sentido com sua vida cotidiana, na perspectiva de análise e compreensão da realidade articulada a uma percepção transformadora, enquanto instrumento de educação com qualidade, é pensar em ressignificar uma concepção de que o conhecimento filosófico apresentada como negativa a construção do conhecimento sistematizado. Nesse contexto, segundo Fialho (2003) das rupturas paradigmáticas da contemporaneidade emergem muitos novos olhares sobre os fenômenos, sobre os saberes, sobre os sujeitos. Uma percepção que procura significar um repensar a fim de permitir um entendimento, compreensão, transformação das complexas estruturas das escolas de nsino médio brasileiras. Desta forma, cabe a escola e aos docentes propor alternativas para um ensino sério e significativo que fuja da ideia clássica de uma aula conteudista que nega todas as possibilidades de indagação, reflexão e inter-relação com os saberes apresentados no currículo de ensino médio. É a partir do entendimento trazido por Pimenta (2000) quando explica que a identidade do professor se baseia na articulação entre os saberes das áreas específicas, com os saberes pedagógicos e os saberes da experiência. Com base nessa fundamentação, de que os professores/educadores são capazes de fazer e refazer suas práxis docente, é que se enfatiza o domínio dos conteúdos trabalhados em sala de forma direta e/ou indireta fundamentando o fazer docente. Como muito bem disse Freire (2011) o ensino e a pesquisa não andam dissociados da prática docente. Todavia, os desafios da manutenção e atualização desses conhecimentos específicos se consolidam como um desafio a ser superado. Nesse contexto Freire (2011), firma ainda a necessidade de uma interface dos conhecimentos específicos com a realidade percebida pelo educando, isto é, é preciso dar sentido ao conhecimento, pois sem historicidade ele é vazio.

Construção de conceitos é a tarefa da Filosofia, o conceito é seu material de trabalho. Assim, não basta refletir acerca do mundo, do outro, de si mesmo, é preciso construir, fabricar conceitos. Novamente, métodos e critérios fazem-se necessários. Como um conceito é construído sobre um plano, o conhecimento deste plano é imprescindível para que o conceito possa ser pensado, criado. Daí a necessidade de conhecimento acerca do mundo, da história da Filosofia, da história e do processo da criação dos conceitos. Severino (2019) em seu livro Filosofia Guia para Professores, salienta que "os conceitos são necessários para o filosofar, lídimo exercício de pensamento rigoroso, que precisa superar toda a forma de senso comum".

A filosofia deve ser assumida como tentativa de elaboração de saídas para problemas concretos, por meio da criação de conceitos. Convém ressaltar, também, a defesa de uma filosofia formadora que busca no desenvolvimento do homem, transformar este em um ser questionador e criador de respostas. Seu ensino não está reduzido a um modelo a ser atingido somente no final do processo, não é formativa no sentido de conformar o ser num modelo acabado, ela é criação, e dessa forma não é sistema de informação e nem de controle, é resistindo a ele, por ser criativa. Pode ser reflexiva sem ser restrita a reflexão, mas não é discussão, uma vez que a mesma gera a contraposição de opiniões visando ao consenso. Ela resiste por ser criadora e isto acontece a partir dos problemas e estes obrigam o nosso pensamento a criação de formas para lidarmos com os mesmos. Sua formação é processo contínuo e único. Dessa maneira, o professor, ele também, é peça fundamental nesse processo. E isso tudo deverá, dentro dessa perspectiva a filosofia ser encarada como tentativa de elaboração de saídas para problemas concretos. Assim, além dos critérios e do modo de pensar da tradição, do consumo e da ciência, o estudante passará a dispor dos critérios e do modo de pensar da filosofia para compor seu pensamento de forma autônoma e autoconsciente.

No entanto, a sua permanência como disciplina regular do Ensino Médio não depende só dos professores das escolas públicas e privadas de nível médio, nem só dos educadores formadores de docentes de Filosofia ou dos acadêmicos, mas de uma organização de todos esses segmentos para garantir a criação e implantação de políticas públicas para o ensino de Filosofia, em especial, e para a educação em unanimidade. 
A Filosofia é essencial na vida de todo ser humano, visto que proporciona a prática de análise, reflexão e crítica em benefício do encontro do conhecimento do mundo e do homem. Leva o estudante à oportunidade de desenvolvimento de um pensar autônomo e crítico, ou seja, permite que ele possa experimentar um pensar individual. Sabe-se que cada disciplina apresenta suas próprias características, bem como auxilia a desenvolver habilidades específicas do pensamento que é abordado.

Um fator a ser levado em consideração que influencia o currículo do Ensino Médio refere-se à cultura atual que vivemos, a qual a partir de um modo de vida pautado na aceleração, velocidade da comunicação e informação conduz a experiência humana a mudanças constantes. Diante desse cenário em que a lógica que desenha a cultura da desvalorização da formação do licenciado em filosofia, também desenha para as condições de atuação do docente a perda do princípio de autoridade.

O professor de filosofia enfrenta muitos obstáculos na sua tarefa. Em meio aos vários obstáculos estão de não conseguir lecionar sua disciplina devido a carga horária insuficiente, falta de interesse dos estudantes, falta de estrutura das escolas, de apoio das autoridades e dos familiares dos estudantes e, por fim, a desvalorização por parte dos governos tanto estadual quanto federal. O fato é que tais posturas geram enormes desafios para o Ensino da Filosofia nas salas de aula do Ensino Médio nos dias de hoje. Especificamente ressaltarei a "motivação do estudante", uma vez que, é um equívoco comum atribuir aos estudantes o mesmo grau de interesse que ele próprio possui para a sua área de conhecimento. Convém primeiro, indagar que motivação pode ter o estudante do Ensino Médio pelo estudo da Filosofia. Ao iniciar o estudo na disciplina, o professor não pode contar com nenhum interesse prévio do estudante pela filosofia, mas deve fazer com que o mesmo adquira o gosto pelas questões filosóficas, partindo dos aspetos concretos da sua vida, refletindo e formando novos conceitos, que o levam a desenvolver um pensamento cada vez mais abstrato. Verifica-se ainda, que o desinteresse pelas aulas de filosofia no Ensino Médio, deriva em boa parte, da falta de compreensão dos conteúdos ou do fato, de que, muitas vezes, o estudante não consegue encontrar significação nesse conhecimento, por isso, o professor deve estar atento à prática de ensino que adota para não favorecer ou alimentar o desinteresse e a indiferença pelas aulas de filosofia. Na impossibilidade com o interesse inicial do estudante para a filosofia, deve-se reconhecer a necessidade de construí-lo. Mas, como criar "um apetite que não existe"?

O interesse pela reflexão filosófica, só poderá ser despertado se os conteúdos se revelarem significativos para o estudante, inscritos no horizonte pessoal de experiências, conhecimentos e valores. Os pré-requisitos do educando devem funcionar como uma espécie de ponto de ancoragem para novas aquisições cognitivas.

A sensibilização do estudante para a filosofia, a possibilidade de que ele se torne receptivo a ela, não é fácil, mas também não é impossível. Parece que o desafio inicial, mais importante, consiste em descobrir aberturas que favoreçam o acesso para os não-iniciados ingressarem no campo filosófico. O professor de filosofia, entre muitas outras tarefas, tem como objetivo peculiar, o de desenvolver no aluno o gosto pela reflexão, o espírito crítico amadurecido, a atenção às causas do que ocorre no nosso redor, tornando-os sensíveis à dimensão ética de cada realidade.

Por isso, os desafios postos pelo ensino da filosofia atualmente, tornam-se necessários não apenas para o rompimento de certas práticas pedagógicas tradicionais, mas também concordar a uma nova concepção de ensino que visa desviar a centralidade da aula no professor, para ter como centro o próprio estudante. Uma vez que só existe ensino se alguém aprende. $O$ ensino da filosofia, não deve gravitar em torno da sabedoria do professor que ensina. $O$ ensino deve girar em torno do estudante, não no discurso do professor. Trata-se, portanto, de colocar do ponto de vista de quem aprende a filosofar e não do ponto de vista de quem sabe filosofar.

Acredito que esse ensino só se concretizará realmente se a sociedade perder seu preconceito para com a filosofia. É urgente superar essa falsa ideia que se tem dessa disciplina, uma imagem 
desvirtuada por uma educação controlada pelo estado. Ela deve ser compreendida como o meio de se descobrir o mundo, interagindo com ele a partir de uma reflexão sobre o mesmo e sua relação com esse, e por isso o seu ensino não só é possível como é necessário para uma educação de qualidade. Um ensino a ser realizado mediante a experiência filosófica diante da qual o professor apresenta-se como orientador e instigador do gosto pela busca do conhecimento pelos seus alunos e isso deve acontecer na prática. Na sua prática e na prática dos estudantes.

\section{ITINERÁRIO DE INSERÇÃO NO ESTÁGIO EM FILOSOFIA: MEMÓRIAS DOS DESAFIOS DA DOCÊNCIA}

O Estágio Curricular Supervisionado (ECS) é um período muito curto, se este for comparado ao longo período de preparação que o aprimoramento das condições e práticas didáticas necessita. Permite ainda a observação da função do educador na atual sociedade e seu empenho na construção e formação cidadã e desenvolvimento da pessoa de cada educando enquanto sujeito único e particular.

Sendo a filosofia uma atividade do pensamento e não uma ciência ou um corpo de conhecimentos consensuais e sistematizados, ela deve ter uma didática própria, que instigue o estudante a pensar de forma autônoma e reflexiva. A mesma não pode ser transmitida como sendo um amontoado de conteúdos que devem ser assimilados e decorados. Desse modo, estaríamos ensinando ao educando o que determinado pensador disse sobre determinado tema, ao invés de possibilitá-lo a desenvolver seu próprio pensamento.

Realizado durante o ano letivo de 2015, o Estágio Curricular Supervisionado em uma escola pública no município de Santa Maria, RS, compreendeu dois momentos, no primeiro semestre de 2015, foram realizadas as observações das aulas da docente que atuava na disciplina. Paralelamente a estas observações, e tendo em vista a realidade e o contexto observados, elaborei o projeto de estágio, a ser executado a partir do segundo semestre de 2015, período este em que eu assumiria as aulas.

Com o início do segundo semestre surge a necessidade da experimentação da prática docência, momento este em que procurei desenvolver da melhor forma possível. O exercício era tornar viável o que havia planejado mediante as observações anteriores. Tais observações pretendiam dar conta da necessidade de uma análise mais criteriosa de alguns aspectos da realidade escolar, especificamente aqueles que dizem respeito à relação didática-filosófica do tripé: estudante-saber-docente.

Desse período de inserção, observação e experimentações práticas, foi possível obter algumas impressões acerca das dificuldades da prática de ensino em Filosofia, tais como a mínima presença de estudantes que, à sua maneira, e por se tratar de alunos do noturno tinham interesse na disciplina; período de paralisações na escola em decorrência da desvalorização por parte do governo estadual para com a educação, resultando na redução de períodos na escola, o que dificultava o trabalho do estagiário dado ao pouco tempo de aula para desenvolver a atividade. Aliado a tudo isso estava o desinteresse por parte dos estudantes, que por mais que se preparasse uma boa aula, ainda assim a frequência em minhas aulas era mínima e as vezes até de somente um estudante.

Apesar de todas essas situações enfrentadas no período do meu estágio com a baixa presença de estudantes em sala de aula, os poucos que frequentavam demonstravam algum interesse pela disciplina para uma turma de noturno.

Penso que diante das dificuldades acima relatadas, o que fica dessa experiência de estágio é que apesar da pouca carga horária, período de paralisações dos docentes, desinteresse pela 
disciplina por parte dos estudantes, ainda assim, penso que os estudantes que frequentaram as aulas tenham adquirido algum conhecimento em relação à disciplina de Filosofia.

\section{CONSIDERAÇÕES FINAIS}

Com este trabalho, percebemos que há um caminho a ser seguido pelos docentes de filosofia e que este pode fazer com que o espaço dela seja ocupado com louvor nas escolas de educação básica. A filosofia pode deixar de ser a disciplina que os estudantes consideram como chata e desinteressante e passar a ser um momento de reflexão e construção de conhecimentos.

A presença da filosofia no Ensino Médio esteve, ao longo da história da educação brasileira, intermitente, traduzida algumas vezes em uma redução gradativa no currículo (Lei n. 4.024/61), outras vezes em uma ausência (Lei n. 5.692/71) ou em uma presença controlada (Lei n. 7.044/82) (ALVES, 2002). Assim, muito se discutiu para que fosse conferido à filosofia o status de disciplina, a fim de que se pudessem concretizar suas potencialidades nesse nível de ensino como algo significativo para a formação do senso crítico dos jovens brasileiros.

Sendo assim, a condição atual da filosofia promovida em 2008 pela Lei n. 11684/08, que inclui a filosofia como disciplina obrigatória nos três anos do currículo do Ensino Médio e que altera o art. 36 da Lei n. 9.394 de 20 de dezembro de 1996, representa algo novo e muito requerido.

A inserção da filosofia como disciplina no ensino médio compreende a necessidade da formação crítica e autônoma do cidadão no final da educação básica, pois esse saber fornece condições para o pensar e agir através da ação reflexiva respondendo e indagando as sociedades contemporâneas. Entretanto, firma o processo democrático no Brasil através da construção da educação emancipadora. Logo, o estudo da filosofia não pode ser entendido como mais uma disciplina que compõe o currículo, mas como uma área do conhecimento que traduz o desenvolvimento da humanidade desde seus primórdios.

A importância da filosofia no ensino médio está na contribuição para a construção da consciência crítica dos estudantes, pois tal disciplina ajuda a derrubar os preconceitos que ora são incorporados a nossa mente por ação das estruturas de dominação, como a mídia e outras. Essa consciência dá ao aluno a capacidade de torna-se cidadão consciente dos seus direitos e deveres, como de buscar por meio da reflexão melhoria na condição atual do mundo vigente.

No ambiente da sala de aula deve se estruturar a partir de quatro pilares: a sensibilização, a problematização, a investigação e a conceituação. O primeiro pilar consiste na motivação do aluno por parte do professor, porque este exerce uma influência profunda no que diz respeito ao incentivo ao pensamento filosófico. O segundo é caracterizado pela apresentação do problema que será abordado, ou seja, a temática a ser trabalhada. O terceiro consiste na compreensão da temática partindo do pensamento dos filósofos (nesta etapa a história da filosofia exerce um papel fundamental), e por fim, a conceitualização que consiste no recriar do pensamento filosófico, nesta fase o pensamento do aluno torna-se autônomo.

A partir do momento em que se retira de um jovem a possibilidade de se desenvolver o seu senso crítico, nossa sociedade estará somente favorecendo a formação de uma cultura de rebanho, de indivíduos caracteristicamente amorfos e anônimos, incapazes de criarem obras que engrandeçam o seu momento histórico ou mesmo de adotarem uma postura ativa, consciente, no decorrer de suas existências. 


\section{REFERÊNCIAS}

ALVES, D. D. P. Filosofia sem filósofos: análise de conceitos como método e conteúdo para o ensino médio. In: JÚNIOR, L. A. S; BIELA, J.(Org.). Filosofia no ensino médio: desafios e perspectivas. Natal, RN: EDUFRN, 2012. p. 67-86.

ASPIS, Renata Pereira Lima: GALLO, Silvio. Ensinar Filosofia - um livro para professores. São Paulo: Alta Mídia e Educação, 2009, p. 152.

ASPIS, Renata. O Ensino de Filosofia no Ensino Médio como experiência filosófica, 2004. 153 p. Dissertação (Mestrado em Educação) Faculdade de Educação, Universidade Estadual de Campinas, 2004.

BOAVIDA, João. Filosofia do ser e do ensinar: proposta para uma nova abordagem. Coimbra: Instituto Nacional de Investigação Científica, 1991.

BRASIL. Lei $\mathrm{n}^{\circ}$ 11.684, de 02 de junho de 2008. Torna obrigatório o Ensino das disciplinas de Filosofia e Sociologia no ensino médio. Brasília - DF.

BRASIL. Lei 4.024, de 20 de dezembro de 1961. Fixa as Diretrizes e Bases da Educação Nacional. Brasília:DF.1961.Disponívelem:<http://www6.senado.gov.br/legislacao/ListaTextolntegral. action?id=75529.htm>. Acesso em: 25 jan. 2010.

BRASIL. Lei 5.692, de 11 de agosto de 1971. Fixa Diretrizes e Bases para o ensino de $1^{\circ}$ e $2^{\circ}$ graus, e dá outras providências. Brasília, DF: 1971. Disponível em: . Acesso em 10 maio de 2010.

CERLETTI, Alejandro. Ensinar Filosofia: da pergunta filosófica a proposta metodológica. In: KOHAN, W. (org.). Filosofia: caminhos para seu ensino. Rio de Janeiro: DP\&A, 2004.

CHAUÍ, Marilena. Convite a Filosofia. Ed. Ática. São Paulo: 2008,p.17

COUTO, Edvaldo Souza; ROCHA, Telma Brito; Identidades contemporâneas: a experimentação "eus" no Orkut. IN: COUTO, Edvaldo Souza; ROCHA, Telma Brito; organizadores. A vida no Orkut: narrativas e aprendizagens nas redes sociais, Salvador: EDUFBA, 2010.p. 13 - 32

FAVARETTO, C. A filosofia e o seu ensino. In: CARVALHO, M.; CORNELLI, G. (Org.).

Ensinar filosofia: volume 2. Cuiabá, MT: Central de Texto, 2013. p. 19-36.

FIALHO, Nadia Hage, Campos do saber: território e universidade. IN: HERADIA, Edmundo A.; FIALHO, Nadia Hage (organizadores) América Latina: Educação, Espaços Culturais e Territorialidade, Salvador: Editora UNEB, 2003.

FREIRE, Paulo; Pedagogia da Autonomia: Saberes necessário à prática educativa, São Paulo: Paz e Terra, 2011.

GALLO, Silvio; KOHAN, Walter O. (Orgs.). Filosofia no ensino médio. Petrópolis: Vozes, 2000.

HIRST, P. O que é ensinar? In: Journal of Curriculum Studies. v.3, n¹, 1971, p.5-18.

KOHAN, Walter Omar. (Org.). Filosofia: caminhos para seu ensino. Rio de Janeiro: Lamparina, 2008.

MATTAR, JOão. Interatividade e aprendizagem IN: LITTO, Fredric M.; FORMIGA, Marcos (organizadores) Educação a distância o estudo da arte. São Paulo: Pearson Education do Brasil 2009. p 112- 120. 
PASMORE, John. O Conceito de Ensino. Caderno de História e Filosofia da Educação. Lisboa, vol.6, outubro 2001.

PIMENTA, Selma Garrido; ANASTASIOU, Lea das Graças Camargo. Docência no ensino superior. São Paulo: Cortez, 2002.

RODRIGO, Lídia Maria. Filosofia em sala de aula: teoria e prática para o ensino médio. Campinas. São Paulo: Autores Associados, 2009.

SEVERINO, Antônio Joaquim. Filosofia: guia do professor: Coleção magistério. Série formação geral. São Paulo,Cortez,2009.

SOARES, Washington Luiz de Oliveira. Um estudo sobre os desafios de ensinar filosofia nas escolas com ensino médio na cidade de Barbacena/MG. São João Del Rei. 2012, 85 p. Dissertação (Mestrado em Educação). Departamento de Educação - Universidade Federal de São João Del Rei, 2012. 